Relato de Pesquisa 



\title{
A PRESENÇA FEMININA NAS INDÚSTRIAS DE LINGERIE NA CIDAde de Franca
}

\author{
Mayara C. Freitas Pereira ${ }^{\star}$ \\ Cléria M. L. Bittar Pucci Bueno ${ }^{\star \star}$
}

\begin{abstract}
Resumo
Dados recentes nos comprovam que as indústrias de lingerie têm apresentado considerável crescimento na cidade de Franca/SP, cuja história sempre se pautou pela indústria do calçado. Devido à crise no setor calçadista, sobretudo em razão da intensificação da concorrência com a indústria dos países asiáticos, muitas grandes fábricas de calçados foram fechadas e, com a dispensa de mão-de-obra, houve um processo de reorganização da estrutura fabril, protagonizado, em especial, por aqueles que buscavam nova inserção no mercado de trabalho. Diante deste quadro nasce uma nova vocação empresarial comandada basicamente por mulheres, e que está abrindo postos de trabalho para outras mulheres - a indústria de lingerie, que vem crescendo notoriamente. Partimos de um pressuposto inicial de que muitas destas mulheres, hoje à frente da incipiente indústria de lingerie, tiveram alguma experiência pregressa nas indústrias calçadistas, que empregam expressiva mão-de-obra feminina, sobretudo nos setores de apara e corte de couro, pintura e embalagem, sem contar os serviços do terceiro setor em que a presença feminina é, em qualquer circunstância, relevante. Já por estarem num ambiente econômico-industrial relacionado à moda, a transposição do calçado para a lingerie, em que pese as diferenças óbvias, representou para estas mulheres um reajuste em suas antigas qualificações como industriárias do calçado. Este estudo, em andamento, tem como fito levantar dados a respeito do histórico dessa incipiente indústria, $e$, através do relato dessas mulheres, conhecer suas trajetórias de vida e as experiências que trouxeram para essa nova realidade. Intenta também reconhecer quais foram as estratégias utilizadas para se reorganizarem nos espaços produtivos, que, em alguns casos é a própria casa, além de conhecer e identificar outras experiências que se articulam, no mundo do trabalho.
\end{abstract}

Palavras-chave: trabalho; mulher; lingerie; liderança.

^ Discente de Psicologia da Universidade de Franca e bolsita PIBIC - Protocolo No 119829/20070. Endereço: Travessa Vicente Mange, $n^{\circ}$ 1321, Jd. Palma - Franca S/P - CEP 14402-102. E-mail: mayaracfp@yahoo.com.br

$\star \star$ Orientadora. Professora do Mestrado em Promoção da Saúde e da Psicologia. Possui graduação em Psicologia pela Universidade de Franca (1992), Mestrado(1998) e Doutorado (2004) em Serviço Social pela Universidade Estadual Paulista Júlio de Mesquita Filho, Pós-Doutorado pelo "Instituto de Estudios Universitarios de la Mujer",(2005) pela Universidade de Valência, Espanha. Especialista em Didática para o Ensino Superior (1999) e Psicomotricidade clínica (Instituto Pieron/2002). 


\title{
THE FEMININE PRESENCE IN THE FEMALE UNDERWEAR INDUSTRY IN FraNCA
}

\begin{abstract}
Recent data show that the female undewear industries in Franca/SP have presented considerable growth in that city which history has always been guided by the footwear industry. Due to the crisis in the footwear sector, especially intensified because of the competition with the industry in Asiatic countries, many major factories of shoes were closed, and with the exemption of labor, there was a process of reorganization of manufacturing structure, played in particular, by those who searched new insertion in the labor market. Facing this framework, a new vocation is born, basically controlled by women and creating jobs for other women - the underwear industry, which is growing sharply. We suppose that many of these women, ahead of today incipient industry of underwear, had some past experience in the shoe industries, which employ significant female workforce, mainly in the sectors of shavings and cutting of leather, painting and packaging, not counting the service of third sector where the presence of women is in any case, significant. We believe it because they are already in an economicindustrial environment related to fashion, so the transposition of the footwear to the underwear manufacturing, in spite of the obvious differences, represented for these women, a readjustment in their old skills used in the footwear industry. This paper ongoing, has the purpose of getting data about the history of this incipient industry, and through the report of these women know their trajectories of life and experiences they have brought to this new reality. It also intends to recognize which were the strategies they used to reorganize themselves in productive spaces, which are, in some cases their homes. In addition, it wants to know and identify other experiences that are articulated in the world of work.
\end{abstract}

Keywords: work; woman; female underwear; leadership.

\section{INTRODUÇÃO}

A cidade de Franca é conhecida, nacional e internacionalmente, como uma cidade que possui um arranjo produtivo local no setor da fabricação de calçados, que inclui o curtimento do couro, a manufatura do calçado e a logística do produto para o país e para o exterior. Outras indústrias assessoram a indústria do calçado, tais como as indústrias de cola, solado, produtos metálicos para calçados, matrizaria e embalagem (BUENO, 2005).

O Pólo de Franca está localizado na região Norte do Estado de São Paulo, a 400 km da capital São Paulo. É o segundo maior pólo produtor do País, mas é o primeiro no segmento 
de calçados masculinos, atividade em que é especializado. Possui 760 indústrias de calçados entre micro, pequenas, médias e grandes, que empregam em torno de $28 \mathrm{mil}$ pessoas. A produção, em 2005, foi de 27,9 milhões de pares de calçados. Deste volume, 8,5 milhões foram exportados, gerando um faturamento de US\$163,4 milhões. O calçado produzido em Franca é exportado para 58 países, tendo seu principal comprador os Estados Unidos com $68,87 \%$ do total de participação (PÓLOS..., Abicalçados, online).

Muitas famílias são dependentes economicamente do calçado, que emprega expressivo contingente de mão-de-obra local. Entretanto, devido às conjunturas econômicas que o país vem enfrentando ao longo principalmente destas décadas, muitas pessoas viram-se desempregadas pela política de "enxugamento" de mãode-obra, e muitas empresas locais foram instaladas em outros estados da nação que oferecem melhores incentivos fiscais.

A queda do dólar deverá causar retração de $20 \%$ nas exportações de calçados em 2005. A indústria de calçados da cidade paulista de Franca exportou 592.133 pares em abril, o que representou uma queda de $20,54 \%$ em relação ao movimento de abril do ano passado (745.238 pares). O faturamento caiu $5,12 \%$, na mesma comparação: atingira US\$ 11,885 milhões e agora totalizou US\$ 11,277 milhões. A forte queda no volume não se repetiu na receita por causa do embarque de calçados de maior valor agregado. Com isso, o preço médio mensal avançou 19,41\%, passando de US\$ 15,95 para US\$ 19,05 . De janeiro a abril, as exportações francanas somaram 2.978 .875 pares e US\$ 53,581 milhões. Foram 3.045.487 pares e US\$ 48,910 milhões em igual período de 2004. Os embarques caíram $2,19 \%$ e a receita cresceu $9,55 \%$. O preço médio no primeiro quadrimestre atingiu US\$ 17,99 e superou em $12 \%$ o anterior (US\$ 16,06). As informações são do Sindicato das Indústrias de Calçados de Franca (PÓLOS..., Brazilianfootwear, online).

Neste contexto, observamos um rearranjo da mão-de-obra dispensada do trabalho anterior, para acomodar a economia local, e é diante desta realidade que assistimos ao nascimento de uma nova "vocação industrial" - as indústrias de lingerie.

Recentemente criada, a COOFAL (Cooperativa dos Fabricantes de Lingerie de Franca), forneceram-nos dados que revelam que constam cadastradas 110 empresas em atividade na cidade, sendo $90 \%$ destas comandadas por mulheres (CARRIJO, 2008). 
Muitas mulheres iniciaram sua participação no mundo do trabalho para ajudar nas despesas de casa, outras, entretanto, já tinham experiência anterior no comércio, algumas como domésticas, e outras em fábricas de calçados. Há de se ressaltar que grande parte destas indústrias nasceu no próprio lar - primeira "unidade doméstica de produção" conforme Engels (1979).

As mulheres têm diante de si uma grande tarefa: a de conciliar o trabalho remunerado, ao adentrar o espaço público, com suas funções domésticas e aspirações pessoais, não sendo diferente com aquelas que estão alocadas nas indústrias de lingerie, ainda que estas representem um setor massivamente constituído pela mão-de-obra feminina em todas as fases da produção, inclusive na logística, passando por atividades mais especializadas como a de estilista.

Conhecer o universo destas mulheres, suas estratégias de conciliação entre trabalho e vida privada, as experiências pregressas que trouxeram para esse novo ramo de atividade foram alguns dos motivos que nos levaram a tomar conhecimento dessa nova realidade local e também da história e do percurso das mulheres que estão ou no comando dessa novidade no parque industrial da cidade, ou que simplesmente atuam como operárias deste setor.

\section{A HISTÓRIA DA LINGERIE: A "INTIMIDADE" EXPOSTA}

Ao pensar no desenvolvimento da indústria de lingerie, temos que remontar a períodos muito distantes na história da humanidade, quando encontramos as primeiras peças íntimas usadas por baixo da roupa social.

A história da lingerie, em seus primeiros registros, mostra modelos de calcinhas que datam do ano 40 a.C. em Roma. Outra peça íntima, a cinta, era feita de pedaços de algodão, linho ou lã que, amarrados na altura dos seios, comprimia o abdômen. O uso de uma espécie de calção, inspirado nos cullotes masculinos, foi introduzido no século XVI por Catarina de Médicis, que o utilizava para montar a cavalo. No século XVII surgiu na Espanha o famoso espartilho, feito de tecido rígido que cobria apenas o abdômen com o objetivo de disfarçar as formas. No final do século XIX, foi criado na França o precursor do sutiã, numa tentativa de oferecer às mulheres mais conforto do que o repressor espartilho.

Em 1914 o sutiã foi devidamente reconhecido e patenteado nos Estados Unidos pela socialite nova-iorquina Mary Phelps Jacob. Era feito com dois lenços, um pedaço de fita cor-de-rosa e um pouco de cordão. A lingerie passou por uma série de transformações ao longo do tempo, acompanhando as mudanças culturais e as exigências de uma nova mulher principalmente durante o século XX.

Curiosamente esta peça do vestuário feminino - o sutiã -, além de servir como uma "metáfora" relacionada ao universo feminino, tornou-se a protagonista de um episódio mundialmente conhecido. Estamos nos referindo ao gesto de milhares de mulheres, que, na década de 1960 do século XX, queimaram seus sutiãs em praça pública como expressivo libelo e repúdio ao tratamento desigual entre mulheres, e ao modelo androcêntrico de se conceber a história e os destinos da humanidade. 
O movimento feminista organizado surgiu nos EUA, na segunda metade dos anos 60. Logo, expandiu-se pelos países do Ocidente, propugnando a libertação da mulher, e não apenas a emancipação. Qual a diferença? Emancipar-se é equipararse ao homem em direitos jurídicos, políticos e econômicos. Corresponde à busca de igualdade. Libertar-se é querer ir mais adiante, marcar a diferença, realçar as condições que regem a alteridade nas relações de gênero, de modo a afirmar a mulher como indivíduo autônomo, independente, dotado de plenitude humana e tão sujeito frente ao homem quanto o homem frente à mulher (BETTO, 2001).

Esse gesto marcou o início do Movimento Feminista, que rapidamente se espalhou pela Europa, América e países de tradição conservadora, encabeçando um movimento que ganhou adeptos dos dois sexos, de diversas classes sociais, culturais e econômicas, representantes de setores da sociedade, além de, obviamente, muitos críticos que viam neste gesto uma transgressão aos valores tradicionais.

Na década de 60, as feministas queimaram sutiãs em praça pública para expressar a necessidade de mudança do papel da mulher na sociedade, iniciando o período em que prevalecia a imagem da mulher masculinizada, necessária para a entrada no mercado de trabalho. As roupas que a tornavam invisível sexualmente, acentuando, em vez disso, a sua competência profissional, dominaram os anos 80. Mas, nesta mesma época, com o início do culto ao corpo e a influência da cantora Madonna, que recriou a moda-fetiche usando em seus shows roupas altamente sensuais, iniciava-se um movimento de modificação da relação feminina com a lingerie. A mulher ideal deveria ter êxito profissional e pessoal, ter o corpo bonito, mas não poderia deixar de lado a sensualidade e o erotismo. E é esta a idéia que prevalece no século XXI, as mulheres progrediram socialmente e profissionalmente, tornaram-se cada vez mais independentes e respeitadas, e de símbolo da opressão feminina, o sutiã tornou-se item indispensável para a sedução e beleza (DE VILÃ..., online).

Rapidamente a indústria de lingerie cresceu em todo o mundo, contando com centenas de fabricantes, no país e no exterior.

Em Franca, em apenas 18 anos de história, registraram-se pouco mais de 100 empresas em atividade, inclusive exportando para outros países (CARRIJO, 2008).

De acordo com dados recentes contabilizados pelo Banco do Povo, que está colaborando nessa fase inicial de organização, mais de 110 pequenas empresas de confecções e roupas íntimas estão cadastradas na Prefeitura. Nem todas, no entanto, fizeram a adesão como fundadoras, processo 
este que é natural e estará sendo conduzido paulatinamente, mediante novos contatos, reuniões e os resultados que começarão a ser mostrados [...] Considerando a existência de 110 pequenos donos de confecções, estima-se com segurança que são mais de 300 empregos gerados neste segmento, onde se houver a participação efetiva, será possível efetuar compras em grupo com preços mais acessíveis, realizar cursos periódicos com o apoio de instituições como o Sebrae e outras, além de conquistar novos mercados, onde o acesso nem sempre é possível em razão das limitações naturais de cada um (COOFAL..., 2007).

\section{OBJETIVOS E RESULTADOS ESPERADOS}

Os objetivos deste estudo foram: levantar dados a respeito da participação feminina na indústria de lingerie na cidade de Franca, conhecer as estratégias de conciliação entre mundo privado e não-privado e o histórico destas indústrias, como também as principais dificuldades e desafios encontrados por elas.

Algumas entrevistas já foram feitas (com a presidente da cooperativa e algumas trabalhadoras e empresárias) e outras estão sendo realizadas com as mulheres que comandam ou que trabalham nestas indústrias. Também estão agendadas entrevistas com agentes de diversos órgãos e entidades locais que possam nos oferecer dados sobre a produção de lingerie, tanto em termos de valores econômicos, como em número absoluto produzido para consumo interno e para a exportação. Estes dados serão levantados junto à esta Cooperativa, no CIESP - Centro das Indústrias do Estado de São Paulo -, no Banco do Povo, no Cadastro Físico da Prefeitura Municipal, e em outras fontes.

A primeira entrevista foi realizada com a presidente da COOFAL, Elisa Carrijo, que nos explicou como foi o passo inicial para começar a trabalhar com a lingerie, e, posteriormente, estar à frente de uma cooperativa:

Eu e minha mãe começamos numa confecção, mas sempre tivemos vontade de fazer alguma coisa, na verdade eu queria fazer biquíni, aí comprei uma máquina. Para começar, fiz algumas peças, mas logo deixei de lado. A minha mãe que trabalhava há 25 anos com sapato resolveu mudar e foi trabalhar numa confecção de lingerie e foi apreendendo, e nesse meio tempo eu entrei lá também, ficamos um ano lá, ai estávamos sem saber o que fazer e desempregada as duas, ai resolvemos tentar fazer por conta própria. A minha mãe foi fazer um curso magistral que têm em Franca, que se chama: "Faça lingerie com a máquina da vovó". Ela viu que era fácil de fazer, e comprou a máquina e começamos a fazer. Compramos a máquina de overloque eu tinha a máquina de biquíni, vendi minha moto para podermos comprar outras máquinas que precisava, e começamos devagar (CARRIJO, 2008, grifo nosso). 
Diante do depoimento dela, podemos vislumbrar os arranjos que tanto ela, como a mãe tiveram que fazer para iniciar esse novo empreendimento. Comprovando nossa hipótese inicial de que muitas mulheres vieram das indústrias de calçado, a mãe de Elisa não é a única, segundo ela mesma nos adianta posteriormente. Em seus cálculos baseados apenas em dados empíricos, crê ser essa situação comum à maioria das mulheres que trabalham na indústria de lingerie em Franca, sendo que algumas delas foram para tal indústria motivadas pelo desemprego gerado pelo recesso nas indústrias de calçado, outras porque quiseram arriscar-se em um empreendimento que perceberam estar dando certo.

\section{CONSIDERAÇÕES FINAIS}

A história das indústrias de lingerie em Franca se confunde, então, com as histórias dessas mulheres - não foi, portanto, um setor já pronto, acabado, com uma tradição que as acolheu. Não, na verdade são elas que estão imprimindo suas marcas, seus conhecimentos acumulados, suas experiências (e inexperiências), seus métodos de "tentativa e erro", para edificar essa nova realidade.

Podemos então afirmar que a lingerie, além de ser um produto destinado ao consumo das mulheres, está-se edificando na cidade de Franca como uma indústria "feita por mulheres", que estão à frente desta como trabalhadoras, estilistas, empresárias e vendedoras.

Ainda que dos 25 cooperados atuais três sejam homens, são elas que estão no comando, pois, por serem empresárias, não poderiam, por força da lei, figurar como cooperadas, sendo, então, seus companheiros os que assumiram a cooperativa. É a mesma situação para as dez empresas chefiadas por homens, em um universo de 110 ao todo; alguns deles têm suas esposas como cooperadas, então, aqui, inverteu-se a situação, pois eles figuram como empresários. Outros ainda o são porque perceberam uma promessa no setor e iniciaram o empreendimento, mas, neste caso, ainda que a empresa esteja em seu nome, quase sempre é um trabalho familiar, em parceria ou mesmo sociedade com outras mulheres, ou suas próprias esposas e filhas.

Estes dados também foram obtidos nessa entrevista com a presidente, e pudemos confirmá-los através de depoimentos espontâneos de outras mulheres, o que será oportunamente checado para que tenhamos todos os dados concretos em termos de números da participação masculina, e em quais cargos.

De posse destes dados históricos, sociais e econômicos, traçaremos a rota dessas mulheres que trabalham ou comandam estas indústrias, com a finalidade de resgatar seu percurso pessoal e as contribuições que tenham trazido para esta nova atividade econômica, visando a uma compreensão do universo da mulher em suas múltiplas relações: o trabalho, os afazeres domésticos, a maternidade, e como as aprendizagens sociais e familiares dadas em função de sua condição de sexo e gênero regulam e norteiam suas escolhas, caminhos e estratégias de sobrevivência e luta. 


\section{REFERÊNCIAS}

BETTO, Frei. Marcas de batom. Caros Amigos. São Paulo, ano V, n. 54, set. 2001. Disponível em: <http://carosamigos.terra.com.br/da_revista/edicoes/ed54/ frei_betto.asp >. Acesso em: 10 set. 2008.

BUENO, C. B. "Vivo sempre preocupada”: o dilema em conciliar (sem culpa) trabalho e maternidade. Franca: Unifran, 2005.

CARRIJO, E. A perspectiva da COOFAL. Entrevista à Mayara C. Freitas Pereira. Franca, 12 abr. 2008.

COOFAL empossa nova diretoria dia 14 próximo. Prefeitura Municipal de Franca. 2007. Disponível em: <http:/www.franca.sp.gov.br:8080/Noticias/ Noticia.jsp?Noticia=3>. Acesso em: 09 set. 2008.

DE VILÃ à mocinha: a saga da lingerie. Fashion Bubbles. Disponível em: $<$ http://fashionbubbles.wordpress.com/2006/05/25/lingerie-conheca-umpouco-da-historia-da-roupa-de-baixo-que-agora-so-quer-aparecer/>. Acesso em: 11 set. 2008.

ENGELS, F. A origem da família, da propriedade privada e do Estado. São Paulo: Civilização Brasileira, 1979.

PÓLOS produtores. Abicalçados. Disponível em: < http://www.abicalcados.com. br/polos-produtores.html\&est=3>. Acesso em: 11 set. 2008.

PÓLOS produtores sentem o efeito do câmbio. Brazilianfootwear. Disponível em: $<$ http://www.brazilianfootwear.com.br/nacional/index.php?pagina=noticia\& $\mathrm{id}=352>$. Acesso em: 11 set. 2008.

Recebido em: setembro de 2008

Aceito em: dezembro de 2008 